\title{
Charpy Impact Response of Glass Fiber Reinforced Composite with Nano Graphene Enhanced Epoxy
}

\author{
Ahmet Erklig ${ }^{1}$, Nurettin Furkan Dogan ${ }^{2}$, Mehmet Bulut ${ }^{3}$ \\ ${ }^{1}$ University of Gaziantep, Engineering Faculty, Mechanical Engineering Department \\ ${ }^{2}$ University of Gaziantep, Engineering Faculty, Mechanical Engineering Department \\ ${ }^{3}$ University of Hakkari, Engineering Faculty, Mechanical Engineering Department
}

\begin{tabular}{l} 
Article Info \\
\hline Article history: \\
Received May $30^{\text {th }}, 2017$ \\
Revised Aug $20^{\text {th }}, 2017$ \\
Accepted Oct $18^{\text {th }}, 2017$ \\
\hline Keyword: \\
Graphene nano platelets, epoxy, \\
glass, composite, low velocity \\
impact
\end{tabular}

Article history:

Received May $30^{\text {th }}, 2017$

Revised Aug $20^{\text {th }}, 2017$

Accepted Oct 18 $8^{\text {th }}, 2017$

\section{Keyword: glass, composite, low velocity}

\begin{abstract}
Fiber reinforced polymer composite materials show several superior properties over conventional engineering materials; on the other hand, most of composite materials also have some drawbacks such as brittle behavior of matrix. This study is aimed to improve the impact response of composite material by adding nano particle into epoxy matrix. For this purpose; an experimental study was conducted to investigate the effect of graphene nano particles inclusion in epoxy resin with glass fiber reinforced composite plate on the Charpy impact response. Glass fiber reinforced (GFR) epoxy composite plates were produced with various graphene nano platelets content such 0 , $0.1,0.25$ and $0.5 \mathrm{wt} \%$. Low velocity impact response was investigated by using Charpy impact test method. Impact energy and impact damage results presented in detail.
\end{abstract}

\section{Corresponding Author:}

Nurettin Furkan Dogan, University of Gaziantep, Engineering Faculty, Mechanical Engineering Department, Turkey, Email: nfurkandogan@gantep.edu.tr

\section{Introduction}

In the past few decades, composite materials have been focused more by the engineering and research world due to their superior performance to weight ratio compared to conventional engineering materials. With these superior performance characteristics, fiber reinforced polymer (FRP) composites have seized the supremacy of usage in marine, aerospace, automobile, and construction industries. In fiber reinforced polymer composites, as the name suggests, fibers are used as a reinforcement materials into resins. Glass fibers are widely used reinforcement type due to their low cost (compared to Kevlar, carbon) and good mechanical properties. And, resin material can be polymer, ceramic or metal based. Epoxy is one of the most used polymer type as resin material. The brittle and poor impact resistance nature of resin has led the researchers to improve these properties of resin with adding micro and nano-sized particles to resin material. Riley et al [1, 2] found that the inclusion of large particle in matrix adversely affects the impact properties of material, since 
they can act like a crack initiation site. Also, they stated that the presence of nanosized fillers can affect the morphology of polymers and improve the toughness of materials in consequence of crack deviating processes.

Carbon nano materials have attracted a huge attention because of their remarkable mechanic, thermal and electrical properties since their discovery [3]. Graphene nano platelets (GnPs) which has been recently developed single layered carbon nano material is a useful polymer reinforcement material which has a large surface area led to increase the stress transfer between polymer and nano material $[4,5,6,7]$. Graphene has a 2-D nanostructure and leads an enhancement in toughness of fibers $[8,9]$. Several researchers reported that the graphene nano material addition in the fiber reinforced composites significantly affects the mechanical [10, 11], dynamic [12], thermal [13] and electrical [14] properties materials. Madhukar et al. [15] stated that GnPs inclusion in unidirectional composites significantly increased the interfacial adhesion and interlaminar shear strength as well as the flexural and tensile properties. Rafiee [16] concluded that the $0.125 \mathrm{wt} \% \mathrm{GnPs}$ incorporation in graphene/epoxy nanocomposite the fracture energy was increased about $115 \%$. Bulut [17] studied the effect of GnPs on the tensile, flexural and impact properties of Basalt fiber reinforced epoxy composite and stated that the addition of $0.1 \mathrm{wt} \% \mathrm{GnPs}$ resulted the increase in impact strength of composite material.

In this study, the influence of graphene nano platelets on the low velocity impact behavior of glass fiber reinforced polymer composites will be investigated experimentally by conducting Charpy impact test. The change in energy absorption property and impact strength will be characterized at different weight ratios of nano material.

\section{Materials and specimen preparation}

\subsection{Materials}

Glass plain fabric having areal weight of $202 \mathrm{~g} / \mathrm{m} 2$ and thickness of $0.15( \pm 5 \%) \mathrm{mm}$ produced by Hexcel Corporation, Italy was used as reinforcement phase. Chemical products of epoxy (MOMENTIVE-MGS L285) and hardener (MOMENTIVE -MGS H285) were supplied from DOST Chemical Industrial Raw Materials Industry in Turkey. Graphene nano Glass plain fabric having areal weight of $202 \mathrm{~g} / \mathrm{m} 2$ and thickness of 0.15 $( \pm 5 \%) \mathrm{mm}$ produced by Hexcel Corporation, Italy was used as reinforcement phase. Chemical products of epoxy (MOMENTIVE-MGS L285) and hardener (MOMENTIVE -MGS H285) were supplied from DOST Chemical Industrial Raw Materials Industry in Turkey. Graphene nano platelets were supplied from GrafNano Technological Materials Industry \& Trade Ltd. Co., Turkey. Nanomaterial has purity of $99.5 \%$, bulk density of $\sim 0.05 \mathrm{~g} / \mathrm{cm} 3,5 \mu \mathrm{m}$ diameter of graphene, thickness of $5-8 \mathrm{~nm}$, and specific surface area of $150 \mathrm{~m} 2 / \mathrm{g}$, as well as Raman spectra ID/IG Ratio of 0.08 and XRD 2-theta of $26^{\circ}$ peak.

Table 1. Material properties

\begin{tabular}{ccc}
\hline Material & Density & Thickness \\
\hline Glass Fabric & $202 \mathrm{~g} / \mathrm{m} 2$ & $0.15 \mathrm{~mm}$ \\
Graphene Nano & $50 \mathrm{~kg} / \mathrm{m} 3$ & $5-8 \mathrm{~nm}$ \\
Platelets & $1.18 \mathrm{~g} / \mathrm{m} 3$ & - \\
Epoxy Resin & & \\
\hline
\end{tabular}

\subsection{Sample Preparation}

The composite material preparation was carried out by vacuum infusion method in Fig.1. Twelve plies of glass fabric were cut into a certain size and laid by [0/90] lay-up sequence. Matrix phase was prepared by mixing the epoxy with hardener in the 100:40 weight ratio as well as different amounts of GnPs $(0.1,0.25$ and $0.5 \mathrm{wt} \%)$. After epoxy was mixed with GnPs filler, the mixture was stirred for $20 \mathrm{~min}$ to reach a good dispersity. Following this step, the mixture was stirred with hardener for 10 min. During composite production, first, all twelve plies were laid on to a thin release agent on production desk, then peel ply and resin infusion mesh were laid on the fabrics. And finally, vacuum bag was sealed onto mesh. After these steps, resin mixture was transferred with the help of vacuumed bag. When the resin mixture impregnated, the 
composite material subjected vacuum $10 \mathrm{~h}$ curing time and under temperature of $45{ }^{\circ} \mathrm{C}$ for $5 \mathrm{~h}$. Nominal thickness of samples was measured as $2.1 \pm 0.1 \mathrm{~mm}$.

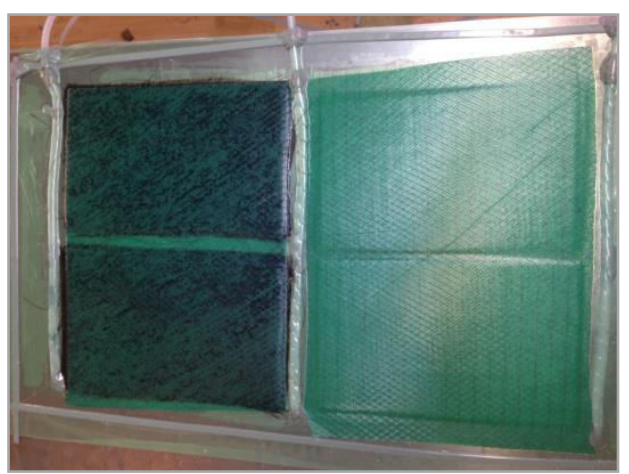

Figure 1. Composite plate production

\subsection{Charpy Impact Test}

In this test, Charpy tests were performed following ISO 179/92 standard [18] with Köger 3/70 Charpy impact test device shown in Fig.2. Both notched and unnotched test specimens with dimensions of $55 \times 10 \mathrm{~mm}$ as seen in Fig. 2(b) were subjected to impact loads flatwise and edgewise respectively. In Charpy impact test device, a pendulum with a defined mass attached to a rotating arm connected to device body. Pendulum falls from a certain height and hits the test specimen and specimen absorbs part of pendulums kinetic energy. The absorbed impact energy and impact strength of material were calculated as follows:

$$
\begin{gathered}
E=E_{1}-E_{2} \\
U=E /(b h)
\end{gathered}
$$

where $E$ is the absorbed energy after impact, $U$ is the impact strength, $E_{1}$ and $E_{2}$ are initial and final potential energies, $b$ and $h$ are width and thickness of the specimen respectively.
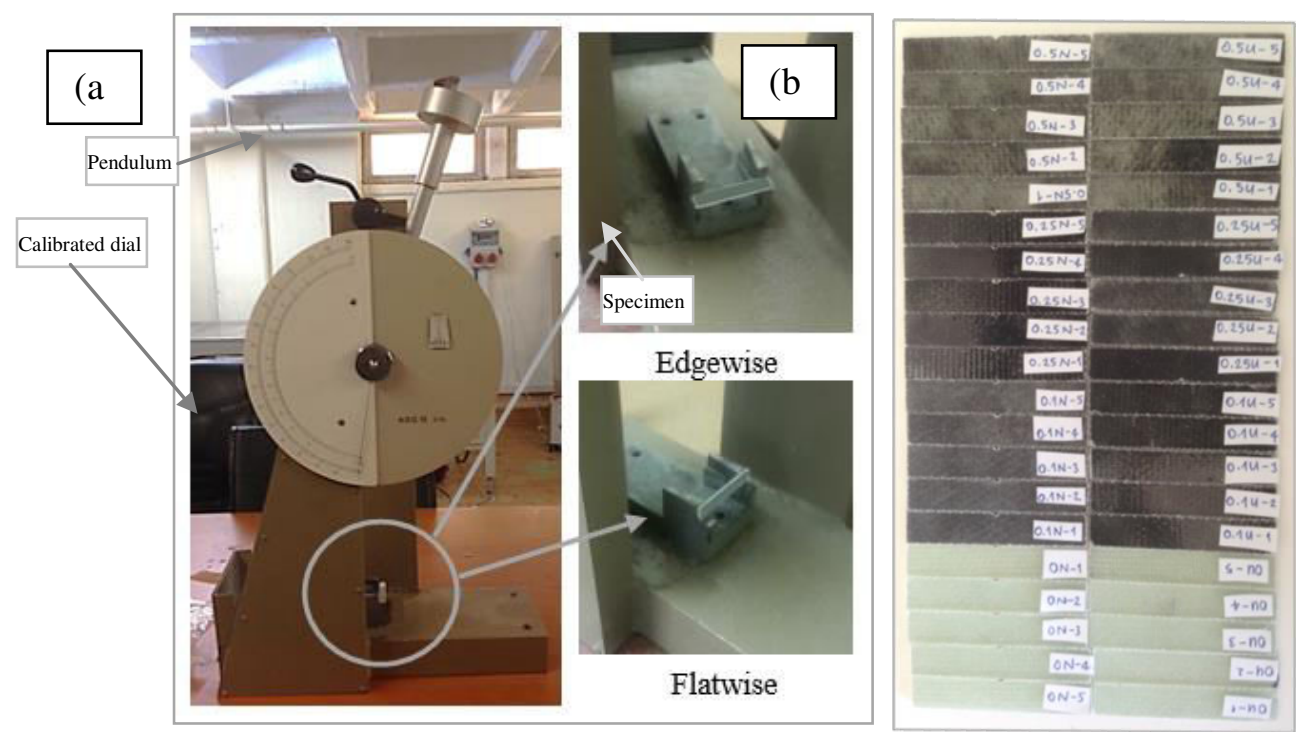

Figure 2. (a) Charpy impact test device and specimen positions, (b) Test specimens

\section{Results and Discussions}

Impact resistance of glass reinforced composite samples was investigated by using Charpy impact test. In experiments notched and unnotched specimens were subjected to impact energy of $15 \mathrm{~J}$ at room temperature. Fig. 3 presents the absorbed energy values of specimens with respect to GnPs contents. It can be seen that subsequent the inclusion of nano particle to matrix, absorbed impact energy values increases drastically. Maximum absorbed energy was reached with the $0.5 \mathrm{wt} \% \mathrm{GnPs}$ inclusion. It was $123 \%$ greater for notched 
and $41 \%$ greater for unnotched specimens than the neat epoxy/glass specimens. In case of impact strength, the variation had the same increasing profile with the absorbed energy variation with respect to GnPs contents. Increase in impact strength can be interpreted as enhancement in bonding between fiber-matrix and nanoparticle. This enhancement also leads to the increase in energy absorption capacity.

The fractured notched and unnotched test specimens after impact load can be seen in Fig. 5. And, it can be observed from figures, delamination failure first decreased $0.25 \mathrm{wt} \% \mathrm{GnPs}$ content, until $0.5 \mathrm{wt} \%$. Also, multiple fiber breakage failure decreased with the GnPs inclusion.

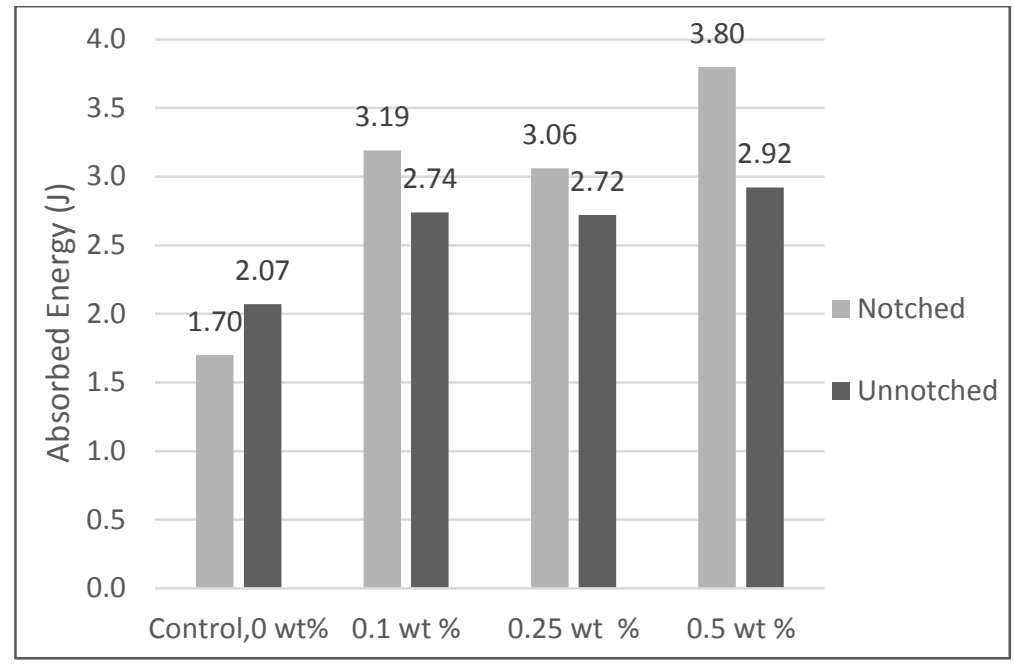

Figure 3. Absorbed energy of notched/unnotched impacted glass fiber reinforced epoxy composites with respect to GnPs content

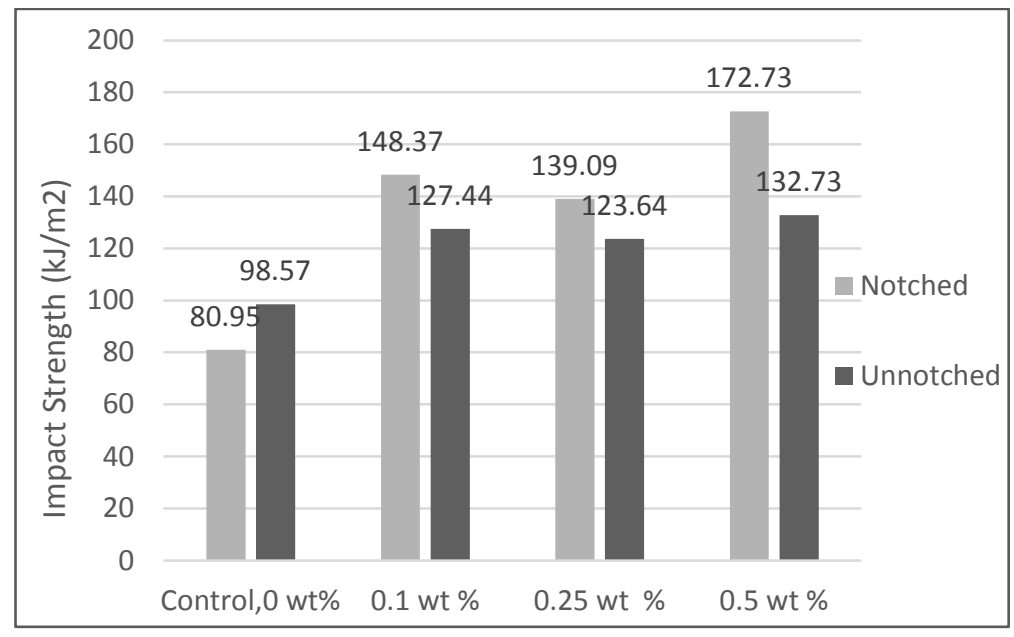

Figure 4. Impact strength of notched/unnotched impacted glass fiber reinforced epoxy composites with respect to GnPs content 


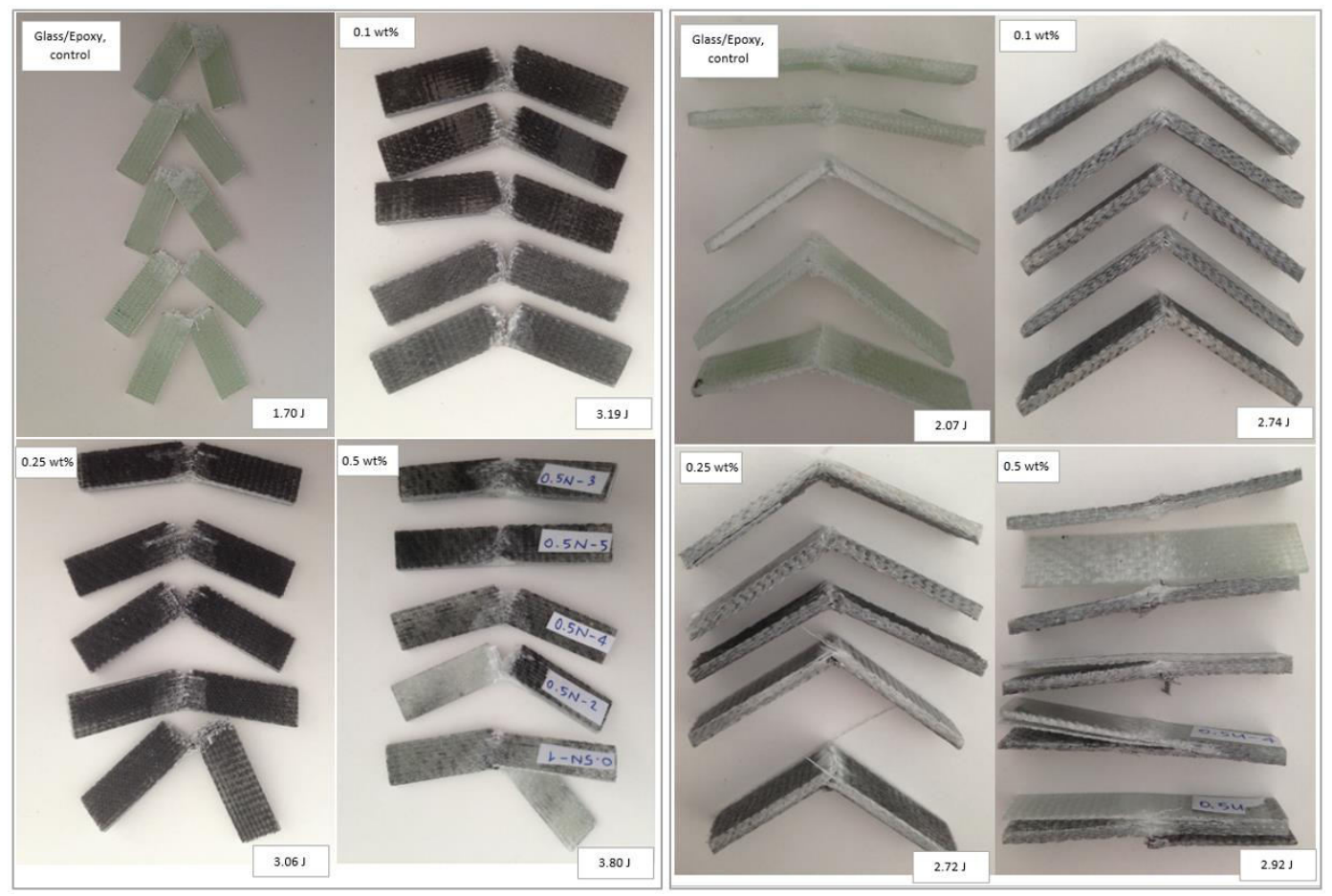

Figure 5. Fractured notched and unnotched specimens

\section{Conclusions}

During experimental study, the Charpy impact properties of glass fiber reinforced (GFR) composite under graphene nano platelets inclusion were studied using notched and unnotched specimens. It can be concluded as the GnPs inclusion in GFR composite improves the impact strength of the material as well as the energy absorption capacities. For notched specimens, this improvement was $123 \%$ and $41 \%$ for unnotched specimens in terms of absorbed energy by $0.5 \mathrm{wt} \% \mathrm{GnPs}$ content. However, presence of delamination failure increased with this content, and it can be interpreted because of nano materials' nature, the agglomeration in particles takes place with the higher content of nano materials.

\section{References}

[1]. A. M Riley., et al. "Factors affecting the impact properties of mineral filled polypropylene", Plastics and rubber processing and applications, (1990), 14.2, pp. 85-93.

[2]. M., Hussain, A., Nakahira, K Niihara, "Mechanical property improvement of carbon fiber reinforced epoxy composites by Al2O3 filler dispersion", Materials Letters, 26(3), (1996), pp. 185-191.

[3]. X. Ji, Y. Xu, W. Zhang, L. Cui, J. Liu, "Review of functionalization, structure and properties of graphene/polymer composite fibers", Compos Part A, 87 (2016), pp. 29-45.

[4]. Rawat, P., Singh, Kalyan Kumar, "An impact behavior analysis of CNT-based fiber reinforced composites validated by LS-DYNA: A review", Polymer Composites, 2015.

[5]. G. Mittal, Y.R. Kyong, J.P. Soo, D. Hui, 1Generation of the pores on graphene surface and their reinforcement effects on the thermal and mechanical properties of chitosan-based composites", Compos Part B Eng, 114 (2017), pp. 348-355.

[6]. M.R. Zakaria, M.H.A. Kudus, H.M. Akil, M.Z.M. Thirmizir, "Comparative study of graphene nanoparticle and multiwall carbon nanotube filled epoxy nanocomposites based on mechanical, thermal and dielectric properties", Compos Part B Eng, 119 (2017), pp. 57-66.

[7]. H.S. Shen, Y. Xiang, Feng Lin, D. Hui, "Buckling and postbuckling of functionally graded graphenereinforced composite laminated plates in thermal environments", Compos Part B Eng, 119 (2017), pp. 6778. 
[8]. B. Zhang, R. Asmatulu, S.A. Soltani, L.N. Le, S.S.A. Kumar, "Mechanical and thermal properties of hierarchical composites enhanced by pristine graphene and graphene oxide nanoinclusions", J Appl Poly Sci, 131 (2014), p. 40826.

[9]. X. Du, H. Zhou, W. Sun, H.Y. Liu, G. Zhou, "Graphene/epoxy interleaves for delamination toughening and monitoring of crack damage in carbon fibre/epoxy composite laminates", Compos Sci Technol, 140 (2017), pp. 123-133.

[10].W. Qin, F. Vautard, L.T. Drzal, J. Yu, "Mechanical and electrical properties of carbon fiber composites with incorporation of graphene nanoplatelets at the fiber-matrix interphase", Compos Part B Eng, 69 (2015), pp. 335-341.

[11].X.Q. Zhang, X.Y. Fan, C. Yan, H.Z. Li, Y.D. Zhu, X.T. Li, et al., "Interfacial microstructure and properties of carbon fiber composites modified with graphene oxide", ACS Appl Mater Interfaces, 4 (3) (2012), pp. 1543-1552.

[12].L.W. Zhang, Y. Zhang, K.M. Liew, "Vibration analysis of quadrilateral graphene sheets subjected to an in-plane magnetic field based on nonlocal elasticity theory", Compos Part B Eng, 118 (2017), pp. 96-103.

[13].S.Y. Huang, G.P. Wu, C.M. Chen, Y. Yang, S.C. Zhang, C.X. Lu, "Electrophoretic deposition and thermal annealing of a graphene oxide thin film on carbon fiber surfaces", Carbon, 52 (2013), pp. 613616.

[14].X. Du, I. Skachko, A. Barker, E.Y. Andrei, “Approaching ballistic transport in suspended graphene”, Nat Nanotech, 3 (2008), pp. 491-495.

[15].M.S. Madhukar, L.T. Drzal, "Fiber-matrix adhesion and its effect on composite mechanical properties: I. In plane and interlaminar shear behavior of graphite/epoxy composites", J Compos Mater, 25 (1991), pp. 932-957.

[16].M.A. Rafiee, J. Rafiee, I. Srivastava, Z. Wang, H. Song, Z.Z. Yu, et al., "Fracture and fatigue in graphene nanocomposites", Small, 6 (2010), pp. 179-183.

[17].ISO 179-181 Plastics - Determination of Charpy impact properties - Part 1: non-instrumented impact test (2010)

[18].Bulut, M., "Mechanical characterization of basalt/epoxy composite laminates containing graphene nanopellets", Composites Part B: Engineering, 2017. 